\title{
Effect of Mixing on Microorganism Growth in Loop Bioreactors
}

\author{
A. M. Al Taweel, ${ }^{1}$ Q. Shah, ${ }^{2}$ and B. Aufderheide ${ }^{2}$ \\ ${ }^{1}$ Department of Process Engineering and Applied Sciences, Dalhousie University, Halifax NS, Canada B3J 2X4 \\ ${ }^{2}$ Process Engineering Programme of The University of Trinidad and Tobago, Point Lisas Campus, Brechin Castle, Couva, \\ Trinidad and Tobago \\ Correspondence should be addressed to A. M. Al Taweel, al.taweel@dal.ca
}

Received 27 January 2012; Accepted 24 May 2012

Academic Editor: Shaliza Binti Ibrahim

Copyright ( $) 2012$ A. M. Al Taweel et al. This is an open access article distributed under the Creative Commons Attribution License, which permits unrestricted use, distribution, and reproduction in any medium, provided the original work is properly cited.

The impact of mixing on the promotion of microorganism growth rate has been analyzed using a multiphase forced-circulation pipe-loop reactor model capable of identifying conditions under which it is possible to convert natural gas into Single-Cell Protein. The impact of mixing in the interphase mass transfer was found to exert a critical role in determining the overall productivity of the bioreactor, particularly at the high cell loadings needed to reduce the capital costs associated with the large-scale production needed for the production of relatively low-value SCP in a sustainable manner.

\section{Introduction}

Industrial biotechnology uses living cells or cellcomponents (yeast, moulds, bacteria, plants, and enzymes) to synthesize products that are easily degradable, require less energy to produce, and create less waste during their production, all of which helps to decrease the environmental impact of this promising manufacturing approach. It is already used to generate large quantities of biobased products in sectors such as: chemicals, food and feed, detergents, pulp and paper, health care, textiles, bioenergy (e.g., biofuels, biogas), photocatalytic algae production, wastewater treatment, bioleaching, and biological site remediation. It also holds the promise of being a credible method for the sustainable development of many other products because it uses renewable raw materials and is capable of achieving very high efficiencies while converting nonrenewable resources to final products with minimum generation of undesirable byproducts/waste. Nevertheless, the shift to the bioprocessing route will happen only if the economic process and market demands justify the transition. However, the growing environmental pressures combined with the rapid developments in the science supporting biotechnology (sequencing of industrial bacterial and yeast genomes, metabolic engineering, bioinformatics and computer-based modeling, and process optimization) are opening up opportunities for new products and cost reductions.

One of the main factors affecting the economic viability of many of the aforementioned operations is the rate at which interphase mass transfer can take place since it is often the parameter limiting the growth rates of microorganisms encountered in many of these biotechnological processes [1-5]. The use of forced-circulation loop reactors holds the promise of overcoming such limitations in a costeffective fashion particularly for large-scale operations [611]. Whereas the achievement of high productivity is usually not a high priority issue in the production of high-value biotechnological products such as medical therapeutics and pharmaceuticals, the relatively low value of the products encountered in industrial biotechnology necessitate that high utilization efficiencies for capital and raw materials be achieved to ensure sustainability $[4,5]$.

The objective of this study is to develop a mathematical model that is capable of quantifying the role that mixing and interphase mass transfer play in the overall performance of pipe-loop bioreactors. Particular emphasis is placed on identifying the value of $k_{L} a$ needed to achieve high overall reactor productivity under different design and operating 
conditions (e.g., biomass loading, bioconversion rates, feed gas composition, superficial liquid velocity, and gas to liquid ratios). Judicious selection of mixing devices can then be made in order to achieve optimal conditions. A case study in which natural gas is converted into Single-Cell Protein is used to illustrate the capabilities of this approach and to identify a range of optimal conditions necessary for sustainable operations. Interest in this technology is driven by the promise of meeting the rapidly increasing worldwide demand for protein-rich nutrition in an energy-efficient and cost-effective fashion [2].

\section{The Role of Mixing in Bioreactors}

Bioreactors are characterized by a complex three-phase flow (liquid, gas, and biomass) and the interaction between mixing and biological reactions is complicated by the fact that such interactions take place simultaneously at the macro-, meso-, and micromixing scales.

Macromixing thus dictates the flow pattern prevalent in the bioreactor and ensures that the nutrients are reasonably well distributed throughout its volume. Large-scale bioreactors have been shown to exhibit heterogeneous hydrodynamic and concentration fields with the cells circulating through such reactors being submitted to an extracellular fluctuating environment [12]. Insufficient macromixing can consequently induce modifications of the cell metabolism, leading to the formation of byproducts and decreasing the overall reactor performance with large-scale cultivations exhibiting lower carbon conversion yields than expected from lab-scale experiments [13]. In the case of the photobioreactors used for algae production, macromixing is used to ensure proper exposure to high-intensity light and to provide alternate durations in light and dark regions, an environmental requirement for some microorganisms to achieve high growth rates and to produce the desirable product quality [14-16].

On the other hand, the Kolmogorov microscales for typical bioreactor configurations vary from 50 to $300 \mu \mathrm{m}$, which is far larger than the size of bacterial or yeast cells ( 2 and $10 \mu \mathrm{m}$, resp.). Microbial cells, which usually have densities very close to the aqueous environment into which they are suspended, are therefore usually engulfed by the liquid stream in which molecular diffusivity becomes the main mechanism responsible for providing substrate to the cells [13]. It is however well accepted that the size of bubbles present in turbulently flowing liquid (a factor which strongly affects the rate of gas exchange) is inversely related to the local energy dissipation rate or the local microscale [17-20]. The same requirements apply to facilitating interphase mass transfer in the liquid-liquid dispersions encountered during the biodegradation of hydrophobic substrates, or when an immiscible liquid phase is introduced to facilitate oxygen transfer [21].

High levels of microscale turbulence are therefore necessary to improve mass transfer between the phases but attention must be given to ensure that shear-sensitive cells are not damaged $[19,22]$. On the other hand, recent findings

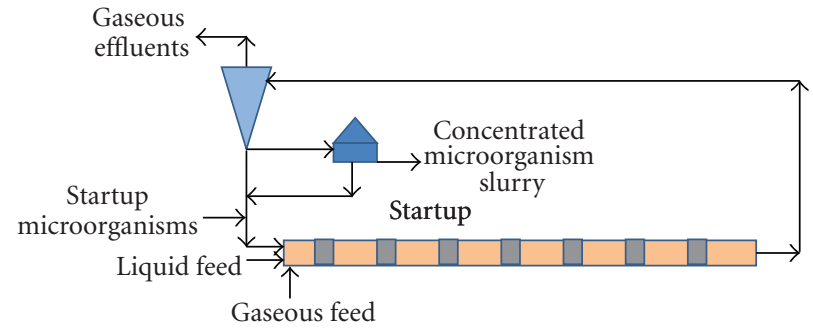

FIGURE 1: Schematic representation of a pipe-loop bioreactor system.

suggest that, contrary to the commonly accepted idea, a beneficial effect on the growth rate of animal cells can be achieved at moderately elevated agitation rates [23].

2.1. Forced-Flow Pipe-Loop Bioreactors. The overwhelming majority of the information dealing with the impact that mixing has on the performance of bioreactors focused on mechanically agitated tanks, bubble columns, and airlift reactors [24], with very limited attention being given to the case of pipe-loop bioreactors although they hold the promise of being used for large-scale industrial bioprocessing because of their uniform plug flow characteristics, ease of control, and low capital and operating costs. To redress this deficiency, attention in the following sections will be focused on analysing the performance of tubular loop bioreactors in which the biochemical reaction rate is usually controlled mainly by mixing and its ability to promote interphase mass transfer. A case study in which natural gas is converted into Single-Cell Protein is used to illustrate the capabilities of this approach.

The operation of a typical pipe-loop bioreactor is schematically represented in Figure 1 in which different reactor configurations can be used:

(i) horizontal, inclined, and vertical closed-loop reactor systems in which the flow is mechanically induced using pumps and static-mixing elements are used to develop the desired flow patterns, gas dispersion, and local energy dissipation rates needed to maintain good contact [3, 25-27],

(ii) vertical U-loop reactors $[8,11]$, in which axial flow mixers/pumps are used to induce the desired flow while static mixers are used at several locations along the loop to redisperse the gas and improve contact between the phases,

(iii) combinations of the above [7].

Regardless of the method used to induce fluid flow (pumps, inline axial flow mixers, or airlift), the process performance of the bioreactor can be described by the same model.

2.2. Interphase Mass Transfer in Forced-Flow Pipe-Loop Bioreactors. Static mixers have become an integral and basic component of the multitude of equipment used in the chemical process industries. Because of their simplicity and 
the absence of any moving parts, these mixers are being increasingly used in a wide range of applications [28]. They are thus used for laminar and turbulent mixing of miscible liquids, in enhancing the performance of heat exchangers and tubular reactors, for laminar and turbulent homogenization, to promote coagulation and flocculation under wellcontrolled hydrodynamic and chemical environment as well as for the dispersion of immiscible phases.

The only source for energy dissipation that is associated with the use of static mixers is that related to the loss of pressure energy as the fluid passes through the static-mixing elements. This is usually supplied by the pump used to circulate the fermentation broth through the reactor loop. The major disadvantage of using static-mixing elements in bioreactors therefore stems from the direct coupling between the local energy dissipation rate within the mixing elements (which controls the rate of interphase mass transfer) and the velocity at which the two phases pass through such elements. This limits, to some extent, the operational flexibility of the systems but the use of multiple mixers operating in parallel can be used to overcome this difficulty.

A typical static mixer is composed of a series of identical, motionless inserts that are installed in tubular structures (pipes, columns, or reactors) with the purpose of redistributing the fluid in a direction transverse to the main flow (i.e., in the radial and tangential directions). The effectiveness of this redistribution is a function of the specific design and number of elements. On the other hand, the recently introduced screen/grid mixing elements can be considered as means for modifying the turbulent characteristics (turbulence scales and intensity) of the pipe flow, thereby providing a high degree of control on the performance of the gas/liquid contact $[20,29,30]$.

Although the patent literature pertinent to static mixers and their use goes back to the 1930s, systematic investigations concerning the various factors affecting gas/liquid contacting and interphase mass transfer in such units are somewhat limited [20, 31-34]. However, the work conducted by Heyouni et al. [17] presents a very systematic investigation of the various factors affecting gas/liquid contacting in static mixers and compared their findings with the performance of other commonly used contactor types such as mechanically agitated tanks, bubble columns, and airlift reactors. They reported that the use of Lightning static mixers can enhance the interfacial area of contact between the phases by a factor of 10-25 with the value of the interphase mass transfer coefficient increasing with increasing liquid and gas velocities. Volumetric mass transfer coefficients as high as $2.5 \mathrm{~s}^{-1}$ were obtained at local energy dissipation rates of about $100 \mathrm{~kW} /$ tonne. Similar results were also reported by several other investigators $[20,33,34]$ at somewhat similar rates of energy dissipation within the volume of the mixer. The impact that various constituents present in fermentation broths have on bubble breakage/coalescence and mass transfer was simulated by Azizi and $\mathrm{Al}$ Taweel by adding trace quantities of a cationic surfactant (up to $20 \mathrm{ppm}$ of SDS). In spite of the well-known adverse effect that surfactants have on the value of the liquid-side mass transfer coefficient $k_{L}$, $[24,35]$, volumetric mass transfer

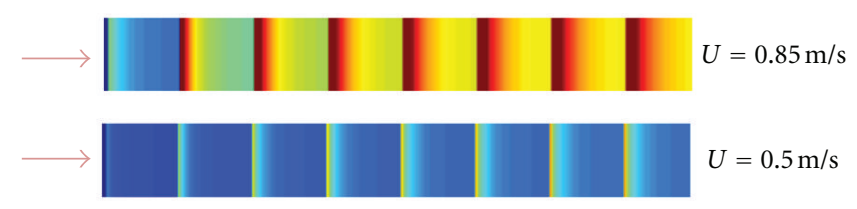

FIGURE 2: Axial variation in local interphase mass transfer coefficient.

coefficients as high as $4.0 \mathrm{~s}^{-1}$ were obtained thanks to the ability of screens/sieves to efficiently generate large interfacial areas of contact.

It is however very interesting to note that whereas static mixers are typically characterized as having very high local energy dissipation rates (with $\varepsilon$ values of up to $1,000 \mathrm{~kW} /$ tonne being reported), the power needed to pump the fermentation broth through the bioreactor can be rather low. Thus whereas Azizi and Al Taweel [34] obtained mass transfer coefficients as high as $4.0 \mathrm{~s}^{-1}$ using average energy dissipation rates within the contactor volume, $\varepsilon$, of $320 \mathrm{~W} / \mathrm{kg}$, the amount of energy used to pump a unit mass of the liquid through the $560 \mathrm{~mm}$ long static mixer, $E_{M}$, was found to be as low as $0.02 \mathrm{kWh} /$ tonne. This is mainly attributable to the low residence times spent within the static mixer. Much smaller values of $E_{M}$ were obtained by Lemenand et al., [36], while using high-efficiency vortex static elements to disperse immiscible fluids.

The aforementioned very high volumetric mass transfer coefficients were obtained by using relatively small interscreen spacing $(70 \mathrm{~mm})$ and high superficial velocities, factors which resulted in reducing the efficiency by which energy is utilized to promote mass transfer between the phases (0.1$0.6 \mathrm{kgO}_{2} / \mathrm{kWh}$, depending on the operating conditions and the interfacial characteristics of the system). These values are an order of magnitude smaller than those reported by $\mathrm{Al}$ Taweel et al. [9] using similar mixing elements placed far apart (with interscreen spacing of 700-1,200 mm) where the emphasis was on achieving high oxygen transfer efficiencies by taking advantage of the coalescence retardation effect of the contaminants.

In the present analysis, it is envisaged that the approach recommended by Turunen and Haario [32] will be adopted. Short sections containing a relatively small number of staticmixing elements will be used to disperse the gas into small bubbles. Each of these sections will then be followed by relatively long sections of empty pipes which are used to provide the loop reactor with the desired residence time. Unfortunately, the fine bubbles formed by the static mixers will tend to coalesce into bigger ones as the dispersion flows into the regions of lower local energy dissipation rates. The overall outcome of these processes is schematically depicted in Figure 2 which presents the axial variation of the local mass transfer coefficient predicted by CFD simulation for two superficial velocities.

The achievement of high interphase mass transfer rates allows for supplying the high oxygen demands associated with the use of high cell loadings, and for the stripping of 
the $\mathrm{CO}_{2}$ that tends to dissolve in the broth particularly at elevated pressures.

\section{Converting Hydrocarbons into SCP}

In this section, the impact of multiphase mixing (and the associated impact on interphase mass transfer) on the performance of forced-flow pipe-loop bioreactors is illustrated using the important industrial biotechnology case where hydrocarbons and hydrocarbon-based products are converted into single-cell protein. This technology is wellestablished and has been practiced for many years [37]. Initially, attention focused on the use of waxy n-paraffins, a byproduct from oil refineries with the primary use of the product being poultry and cattle feed. Because of the abundance of relatively low-cost natural gas, and the fast conversion rates achievable at lower hydrocarbon molecular weights, emphasis has recently shifted towards using several methanotrophic microorganisms in a continuous process that simply uses methane, oxygen, ammonia, minerals, and water as raw materials. This approach was so successful that a joint venture between Statoil and DuPont (Norferm A/S) constructed a 10,000 tpa plant in Norway that utilized circulating loop reactors with both horizontal and vertical sections in which static mixers were introduced to enhance gas/liquid mass transfer. Commercial-scale production began in May 2003, but was shut down after 3 years presumably because of the low production rate per unit volume of the reactor and the relatively high cost of natural gas supply.

3.1. Pipe-Loop Bioreactors for SCP Production. The continuous manufacture of proteins by the biochemical oxidation of gaseous hydrocarbons in the presence of a nitrogenous nutrient has been achieved using horizontal and vertical closed-loop reactors, vertical airlift reactors, as well as vertical U-loop reactors $[10,11,27,38]$. These investigations, as well as many others, identified that the productivity of this process is influenced by a wide range of parameters such as the liquid phase concentration of oxygen, methane and $\mathrm{CO}_{2}$, the biomass concentration, temperature, and $\mathrm{pH}$.

Although the process is relatively simple, the reactor design methodology is rather complex as it deals with a multiphase system (gas/liquid/solid) in which the gaseous reactants have to dissolve into the aqueous medium where a highly exothermic heterogeneous biochemical reaction takes place.

The model presented in this paper takes into account the most critical components affecting the various processes taking place within the bioreactor used for converting natural gas into SCP. It can be used to design and evaluate the performance of vertical and horizontal tubular loop reactors, as well as the riser section of an Air-Lift Reactor where most of the interphase mass transfer takes place. The model calculates the spatial variation in biomass production as the multiphase reacting mixtures flow along the length of the pipe-loop reactor and can therefore be used for (i) identifying the operating conditions under which the overall production rate is mass transfer limited or reaction rate limited,

(ii) identifying the optimum design and operating conditions such as reactor length, superficial liquid velocity and the gas to liquid flow ratio, and optimum biomass concentration in the recycle stream,

(iii) determining the impact of promoting interphase mass transfer by preconcentrating the oxygen in the gas stream (by switching from air to cryogenic oxygen), operating at elevated pressures, and the insertion of static mixers at various locations along the reactor length,

(iv) calculating the impact of the various design and operating conditions on the energy dissipation rates in the various components of the process, thereby enabling the identification of the optimum balance between capital and operating costs,

(v) identifying the optimum oxygen to methane ratio and the conditions under which it is necessary to recycle and reuse unconsumed raw materials (natural gas, methanol, oxygen, and ammonia).

Better understanding of the interaction between those parameters is needed in order to develop sustainable means for converting natural gas and methanol into SCP.

3.2. Specific Conditions for M. capsulatus SCP Production. Bioreaction stoichiometry can vary significantly depending on the value of a host of parameters that include growth media optimization, temperature, and pressure of the reaction. The SCP produced by the biooxidation of natural gas using mostly $M$. capsulatus contains about $70 \%$ crude protein, $10 \%$ crude fat, $10 \%$ nucleic acid, and $7 \%$ ash and can be represented by the elemental analysis $\mathrm{CH}_{1.8} \mathrm{O}_{0.5} \mathrm{~N}_{0.2}$. Nielsen et al. [39] presented the following stoichiometry for the biooxidation of natural gas (mainly methane) with ammonia and oxygen using the aforementioned microorganism:

$$
\begin{aligned}
\mathrm{CH}_{4}+0.104 \mathrm{NH}_{3}+1.45 \mathrm{O}_{2} \longrightarrow & 0.52 \mathrm{CH}_{1.8} \mathrm{O}_{0.5} \mathrm{~N}_{0.2} \\
& +0.48 \mathrm{CO}_{2}+1.69 \mathrm{H}_{2} \mathrm{O}
\end{aligned}
$$

The corresponding reaction yield coefficients are given in Table 1.

According to Joergensen and Degn [40] the specific growth rate of $M$. capsulatus, $\mu_{s}$, during the biooxidation of methane at $45^{\circ} \mathrm{C}$, can be described by the following Monod equation with the saturation constant values given in Table 1 :

$$
\mu_{S}=\frac{\mu_{\max } C_{S, l}}{K_{S M}+C_{S, l}} .
$$

\section{Modeling the Performance of Forced-Circulation Loop Bioreactors}

Analysis of a bioreactor performance requires a model for the flow field, a model for the biomass reactions taking 
TABLE 1: Baseline parameters used in simulations.

\begin{tabular}{lccccc}
\hline Parameter & Value & Units & Parameter & Value & Units \\
\hline$\mu_{\max }$ & 0.37 & $\mathrm{hr}^{-1}$ & $T_{\mathrm{STP}}$ & 25 & ${ }^{\circ} \mathrm{C}$ \\
$K_{S}$ & $1.3 e^{-6}$ & $\mathrm{~mol} \mathrm{CH}_{4} / \mathrm{L}$ & $P_{T}$ & 3 & $\mathrm{~atm}$ \\
$Y_{S X}$ & 1.93 & $\left(\mathrm{~mol} \mathrm{CH}_{4} / \mathrm{mol} \mathrm{Cell}\right)$ & $P_{\mathrm{STP}}$ & 1 & $\mathrm{~atm}$ \\
$Y_{\mathrm{OX}}$ & 2.80 & $\left(\mathrm{~mol}_{2} / \mathrm{mol} \mathrm{Cell}\right)$ & $U_{\mathrm{G}, 0}$ & 0.043 & $\mathrm{~m} / \mathrm{s}$ \\
$Y_{\mathrm{CX}}$ & 0.92 & $(\mathrm{~mol} \mathrm{CO} / \mathrm{mol} \mathrm{Cell})$ & $U_{\mathrm{L}}$ & 0.5 & $\mathrm{~m} / \mathrm{s}$ \\
$H_{\mathrm{CH}_{4}}$ & $1,000.9$ & $\mathrm{~L} \cdot \mathrm{atm} / \mathrm{mol}$ & $y_{\mathrm{CH}_{4,0}}$ & 0.40 & {$[-]$} \\
$H_{\mathrm{O}_{2}}$ & $1,100.81$ & $\mathrm{~L} \cdot \mathrm{atm} / \mathrm{mol}$ & $y_{\mathrm{O}_{2,0}}$ & 0.58 & {$[-]$} \\
$H_{\mathrm{N}_{2}}$ & $2,023.6$ & $\mathrm{~L} \cdot \mathrm{atm} / \mathrm{mol}$ & $y_{\mathrm{N}_{2,0}}$ & 0.02 & {$[-]$} \\
$H_{\mathrm{CO}_{2}}$ & 47.39 & $\mathrm{~L} \cdot \mathrm{atm} / \mathrm{mol}$ & $y_{\mathrm{CO}_{2,0}}$ & 0.00 & {$[-]$} \\
$T$ & 45 & ${ }^{\circ} \mathrm{C}$ & $Z$ & 15 & $\mathrm{~m}$ \\
\hline
\end{tabular}

place in the liquid phase, and a model for the mass transfer between phases (from gas to liquid and from the liquid to biomass). Despite the fact that biological reactions are conditioned by the mass transfer between the liquid and the biomass, hydrodynamics and bioreactions are generally coupled through conservation equations for the dissolved species.

For properly designed forced-circulation loop reactors operating at the relatively high Reynolds numbers encountered in large-scale operations, the tendency of bubbles to segregate under the action of gravity can be neglected particularly when static mixers are inserted to counteract the tendency for phase segregation and to redisperse the gas phase into finer bubbles $[33,41,42]$. The bioconversion taking place in such reactors can then be well represented by the simple plug-flow multiphase reactor loop in which the microorganisms can be considered as fully dispersed into the liquid phase (Figure 3).

The rate of interphase mass transfer that can be achieved in such a reactor depends on the type of static mixer used, the spacing between mixing elements, the superficial velocity of the liquid, the interfacial characteristics of the system, and the volume fraction occupied by the gas in the two-phase flowing system $[17,20,27,31-34]$. In this investigation, emphasis is therefore placed on developing better understanding of the role that interphase mass transfer plays in determining the overall bioreaction rate, and how it interacts with different design and operating conditions. Subsequent publications will address means by which optimum mixing conditions can be achieved in pipe-loop bioreactors.

The characteristics of the bubbly flow system passing through the control element depicted in Figure 3 is determined by the physical properties of the two phases, their respective flow rates, and the extent to which the gas phase is dispersed through the liquid. The microorganisms suspended in the liquid phase usually have a density that is close to that of water and their volumetric flow rate can, at present, be incorporated as a part of the liquid phase. At relatively low volumetric concentrations (up to $30 \mathrm{~g}$ cells/L dry weight) the presence of bacteria in water will exert little influence on its characteristics but, the rheology of the microbial suspensions can become more complex at

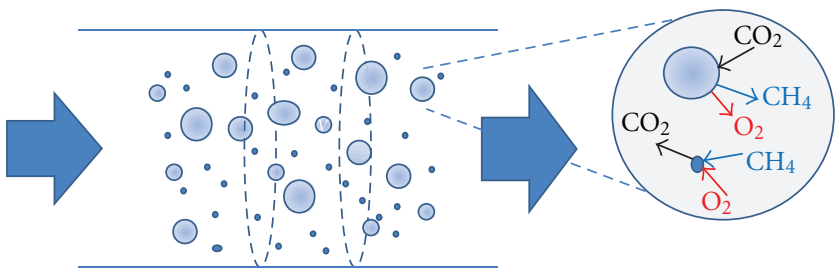

FIGURE 3: Schematic representation of the bubbly flow and interphase mass transfer, taking place in pipe-loop bioreactor.

high-volumetric solid loadings of interacting and flocculated microorganisms [43].

The operational characteristics of the multiphase bioreactor are usually based on the volumetric flow rate of the liquid phase to be processed (which includes the suspended microorganisms as an integral part of it) and the gas to liquid volumetric flow ratio, $G / L$. The latter is usually taken at STP $\left(25^{\circ} \mathrm{C}\right.$, Pressure $\left.1 \mathrm{~atm}\right)$ and does therefore not necessarily reflect the actual conditions present in the reactor which can operate over a wide range of temperatures and pressures.

The total number of gaseous molecules introduced to the reactor is therefore given by

$$
N_{G 0}=\sum_{i=1}^{i=n} \frac{F_{G, i} P_{\text {STP }}}{R T_{\text {STP }}}
$$

where $F_{G, i}$ is the gas flow rate (at STP) for each of the $i$ th gases introduced to the reactor and $n$ is the total number of gaseous species encountered in the bioreactor.

Consequently, the volumetric flow rate of the gas phase at any particular point along the reactor length, $Q_{G}$, can be determined from

$$
Q_{G}=\frac{N_{G 0} R T}{P_{T}} .
$$

And the superficial velocity of the gas phase flowing through the control element, $U_{G}$, can be expressed by,

$$
U_{G}=\frac{Q_{G}}{A_{c}},
$$

where $A_{c}$ is the cross-sectional area of the loop reactor. 
Similarly, the superficial velocity of the liquid phase flowing through the element, $U_{L}$, can be expressed by

$$
U_{L}=\frac{Q_{L}}{A_{c}} .
$$

The superficial velocity of the two-phase system can therefore be expressed as

$$
U_{T}=U_{G}+U_{L}
$$

Neglecting the slip velocity between the phases, a reasonable assumption in finely dispersed bubble flows, the volume fraction of the gas phase (i.e., the gas holdup) can be expressed as

$$
\varepsilon_{G}=\frac{Q_{G}}{Q_{G}+Q_{L}} .
$$

The total number of gas molecules flowing through the control element is determined by the flow rate of the various gaseous constituents fed into the reactor, minus those quantities that have been transferred into the liquid phase, as well as by the various gaseous products that evolve as a result of the biochemical reaction taking place. Parts of the latter gases dissolve into the liquid phase with the remainder being transferred into the bubbly flow gas phase (including water vapour which can play a significant role at relatively high operating temperatures).

Since there is no biochemical reaction taking place in the gas phase, the axial evolution of the reactant concentrations (in the gas and liquid phases) along the length of the reactor can be described by

$$
\begin{gathered}
\frac{d C_{\mathrm{CH}_{4}, G}}{d z}=\frac{-\left(k_{L} a / \varepsilon_{G}\right)\left(C_{\mathrm{CH}_{4}}^{*}-C_{\mathrm{CH}_{4}, L}\right)}{U_{T}} \\
\frac{d C_{\mathrm{CH}_{4}, L}}{d z}=\frac{\left(k_{L} a /\left(1-\varepsilon_{G}\right)\right)\left(C_{\mathrm{CH}_{4}}^{*}-C_{\mathrm{CH}_{4}, L}\right)-Y_{S X} \mu C_{X}}{U_{T}} \\
\frac{d C_{\mathrm{O}_{2}, G}}{d z}=\frac{-\left(k_{L} a / \varepsilon_{G}\right)\left(C_{\mathrm{O}_{2}}^{*}-C_{\mathrm{O}_{2}, L}\right)}{U_{T}} \\
\frac{d C_{\mathrm{O}_{2}, L}}{d z}=\frac{\left(k_{L} a /\left(1-\varepsilon_{G}\right)\right)\left(C_{\mathrm{O}_{2}}^{*}-C_{\mathrm{O}_{2}, L}\right)-Y_{O X} \mu C_{X}}{U_{T}} \\
\frac{d C_{\mathrm{CO}_{2}, G}}{d z}=\frac{-\left(k_{L} a / \varepsilon_{G}\right)\left(C_{\mathrm{CO}_{2}}^{*}-C_{\mathrm{CO}_{2}, L}\right)}{U_{T}} \\
\frac{d C_{\mathrm{CO}_{2}, L}}{d z}=\frac{\left(k_{L} a /\left(1-\varepsilon_{G}\right)\right)\left(C_{\mathrm{CO}_{2}}^{*}-C_{\mathrm{CO}_{2}, L}\right)+Y_{C X} \mu C_{X}}{U_{T}}
\end{gathered}
$$

The values of the yield coefficients $Y_{S X}, Y_{O X}$, and $Y_{C X}$ are given in Table 1 for the case when Methylococcus capsulatus is used to convert methane into SCP.

In addition to the reactants, the gases introduced to the bioreactor usually contain an amount of inerts (nitrogen and rare gases) the value of which depends on the composition of the oxygen source as well as that of the natural gas. Although these gases do not take part in the biooxidation reaction, they partially dissolve in the liquid stream circulated through the loop reactor and their presence in the gas phase results in reducing the concentration of the reactants present in that phase and can, therefore, adversely affect the mass transfer rates. The same applies to the case of the $\mathrm{CO}_{2}$ produced as a result of the biochemical reaction.

The axial variation of the inert gas concentration in the gaseous and liquid phases is given by

$$
\begin{array}{r}
\frac{d C_{\text {Inert }, G}}{d z}=\frac{-\left(k_{L} a / \varepsilon_{G}\right)\left(C_{\text {Inert }}^{*}-C_{\text {Inert }, L}\right)}{U_{T}}, \\
\frac{d C_{\text {Inert }, L}}{d z}=\frac{\left(k_{L} a /\left(1-\varepsilon_{G}\right)\right)\left(C_{\text {Inert }}^{*}-C_{\text {Inert }, L}\right)}{U_{T}} .
\end{array}
$$

Although the mass transfer coefficient for the various gases can be significantly different, they are assumed to be equal for the purpose of this investigation. The equilibrium concentrations present at the gas/liquid interface used in (9)(16) were computed using Henry's law,

$$
C_{i}^{*}=\frac{y_{i} \cdot P}{H_{i}}
$$

where the values of Henry's constant for the various gases are based on the standard values reported in Table 1 but corrected for the bioreactor operating temperature using a van't Hoff equation. The vapour pressure of water present at the interface was estimated using the Antoine equation.

\section{Results and Discussion}

The system of nonlinear ODE describing the fermentation of $M$. capsulatus in a single pass, (3)-(17), was solved using MATLAB's ODE solvers. The impact of various design and operating parameters on the performance of the reactor was numerically determined with the objective of identifying optimum design and operating conditions using the productivity per unit volume as a preliminary indicator. Pressure losses due to the flow through the static mixers and along the reactor length was neglected at this stage of analysis.

Throughout the present investigation, the oxygen to methane ratio was kept at the stoichiometric value of 1.45 . The $15 \mathrm{~m}$ long loop bioreactor was assumed to operate at the optimum temperature of $45^{\circ} \mathrm{C}$ by providing means for removing the heat released through the biooxidation reaction. The oxygen stream is also assumed to be from cryogenic distillation $\left(97 \% \mathrm{O}_{2}\right.$ with $3 \%$ inerts) except where the effect of using different oxygen enrichment methods was assessed. In cases where the methane and oxygen are completely consumed prior to leaving the tubular reactor, the set of differential equations reduces to only the liquid phase for the remainder of the reactor. This was necessitated because a singularity in the gas phase equations occurs as the gas fraction approaches zero.

To reduce the computational effort associated with the analysis of this complex process at this early stage of process 


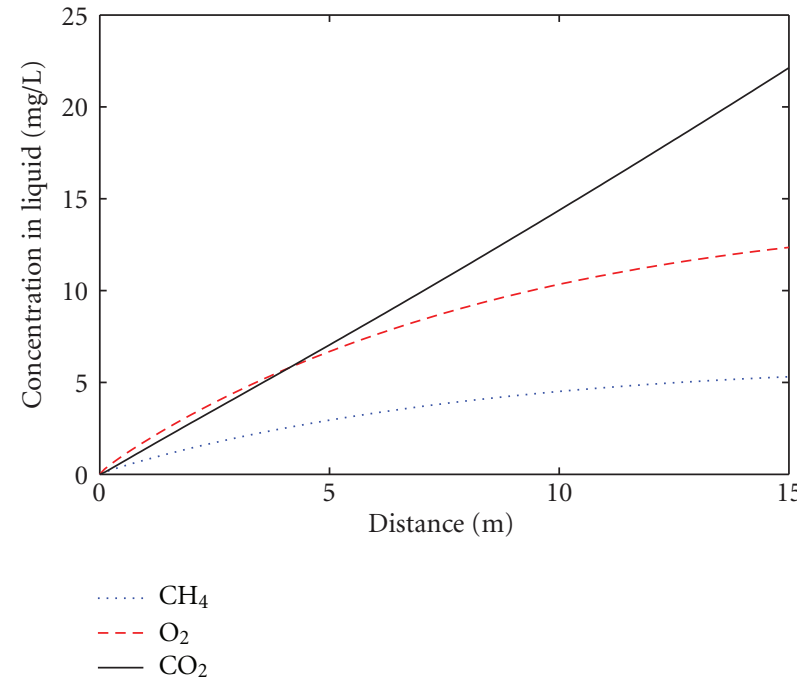

(a) Broth concentrations

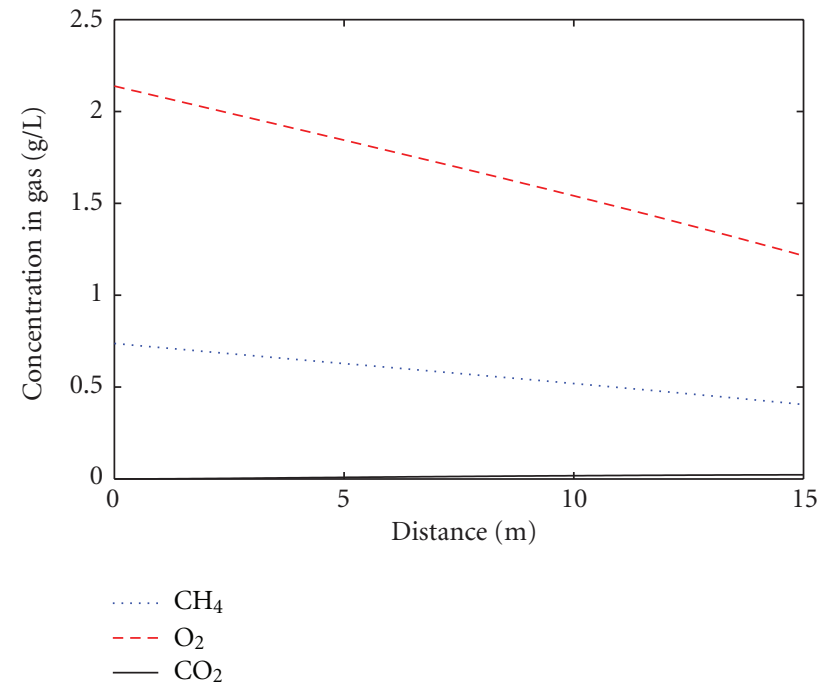

(b) Bubble concentrations

FIGURE 4: Startup concentration profiles in the liquid and gas phases $\left(P_{T}=3 \mathrm{~atm}, k_{L} a=0.05 \mathrm{~s}^{-1}, C_{X 0}=5 \mathrm{~g} / \mathrm{L}, G / L=0.20\right.$, and $\left.U_{L}=0.5 \mathrm{~m} / \mathrm{s}\right)$.

assessment, it was assumed that the dissolved gases are flushed out from the recycled liquid stream which is then returned to the reactor after it is presaturated by the reactants (95\% of max achieved at the operating temperatures pressures).

5.1. Startup Operations. In the liquid phase, where the biooxidation reaction takes place, the axial variation of the reactants $\left(\mathrm{CH}_{4}\right.$ and $\left.\mathrm{O}_{2}\right)$ and product $\left(\mathrm{CO}_{2}\right)$ concentrations is controlled by the relative magnitude of the rate at which the reactants are supplied to the liquid phase (through interphase mass transfer) and the rate at which they are consumed through the biooxidation microbial activity. During the startup stage, the bioreaction is initiated by introducing a small amount of the bacterial inoculums to the recirculating liquid followed by the introduction of the reactant gases at the desired pressure. To accurately simulate this transient stage, the concentration of the reactants in the liquid phase entering the loop was set at zero but was found to increase along the reactor length due to the absorption and/or gas evolution associated with the microbial growth (Figure 4).

On the other hand, the concentration of the reactants in the gas phase decreases as the dispersion progresses along the reactor length with very low concentrations of $\mathrm{CO}_{2}$ appearing in the gas phase due to its progressive accumulation in the liquid phase where it is very soluble at the relatively high pressures used in this case. Due to the low biomass loadings used at startup, the gaseous reactants $\left(\mathrm{CH}_{4}\right.$ and $\left.\mathrm{O}_{2}\right)$ are not fully consumed in the bioreactor and large quantities of the gaseous reactants may need to be flared or recirculated until sufficient biomass loadings have been built up.

This transit situation continues with complete recirculation of the liquid at progressively higher concentration of the microorganisms until a quasi-steady state is reached in which the SCP can be harvested. Since harvesting is typically conducted at atmospheric pressure, most of the gases dissolved in that liquid stream will flash out before the liquid is returned back to the reactor (Figure 1).

\subsection{Effect of Mixing and Promotion of Interphase Mass Trans-} fer. The relative importance of interphase mass transfer and reaction rates is clearly shown in Figure 5. At relatively low volumetric mass transfer coefficients, the average productivity of the bioreactor is limited by the rate at which the gaseous reactants are transported into the liquid phase. On the other hand, the reactor productivity is controlled by the intrinsic biooxidation rate at high mass transfer coefficients with the transition point between the two regimes being a function of the different design and operating conditions.

The length of reactor needed to achieve $>99 \%$ utilization of the reactants was found to decrease as the value of the interphase mass transfer coefficient and biomass loadings are increased. This suggests that the process can be operated at somewhat higher gas/liquid ratios, or that shorter reactor lengths can be used, in order to ensure maximum utilization of the reactor volume. Both of these options can have significant impact on enhancing process sustainability.

The importance of using a combination of high cell loading and high volumetric mass transfer coefficients is demonstrated in Figure 6. For the design and operating conditions tested, the fraction of reacting gases that get converted in a single pass through the loop was found to increase from about $20 \%$ up to about $100 \%$ as the cell loading is increased from 3 to $15 \mathrm{~g} / \mathrm{L}$ provided that the mixing intensity is high enough to supply the microorganisms with the nutrients they need to grow. The overall complexity of the conversion process becomes much simpler if practically all the reactants are consumed within a single pass, thus avoiding need for the complex and costly operations needed to separate and recycle the unused reactants. There is, however, some indications that it is necessary to maintain a minimum level of oxygen 


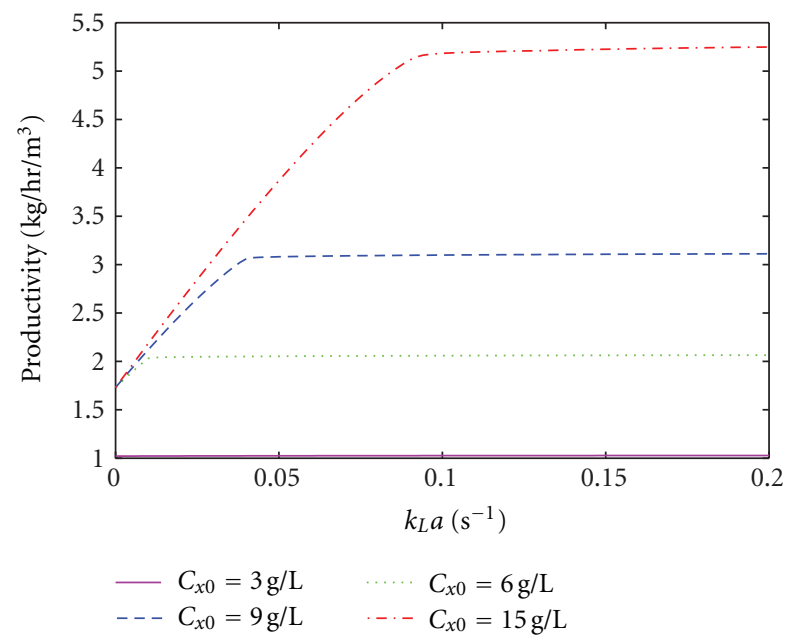

FIGURE 5: Effect of the volumetric mass transfer coefficient on the reactor productivity $\left(P_{T}=3 \mathrm{~atm}, G / L=0.20\right.$, and $\left.U_{L}=0.5 \mathrm{~m} / \mathrm{s}\right)$.

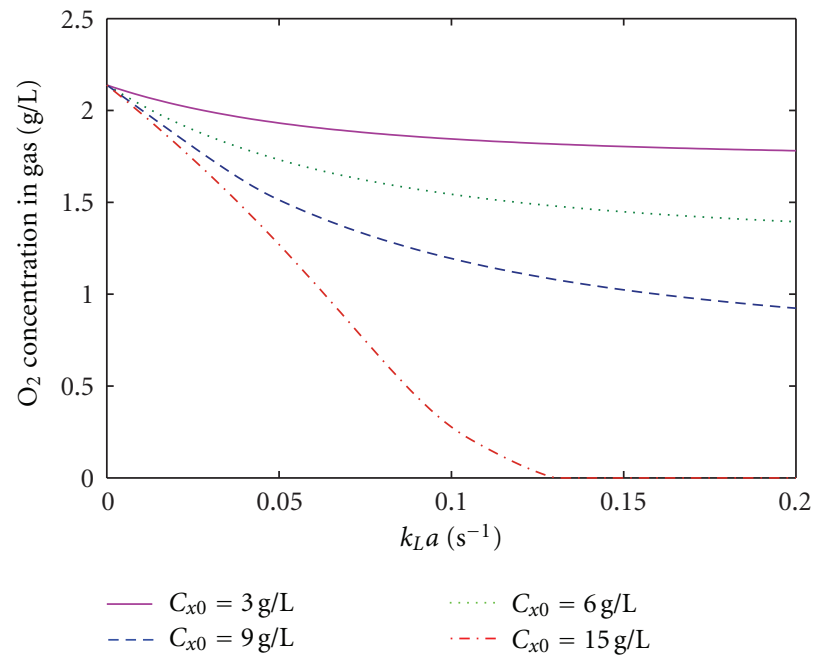

(a) Bubble oxygen concentration

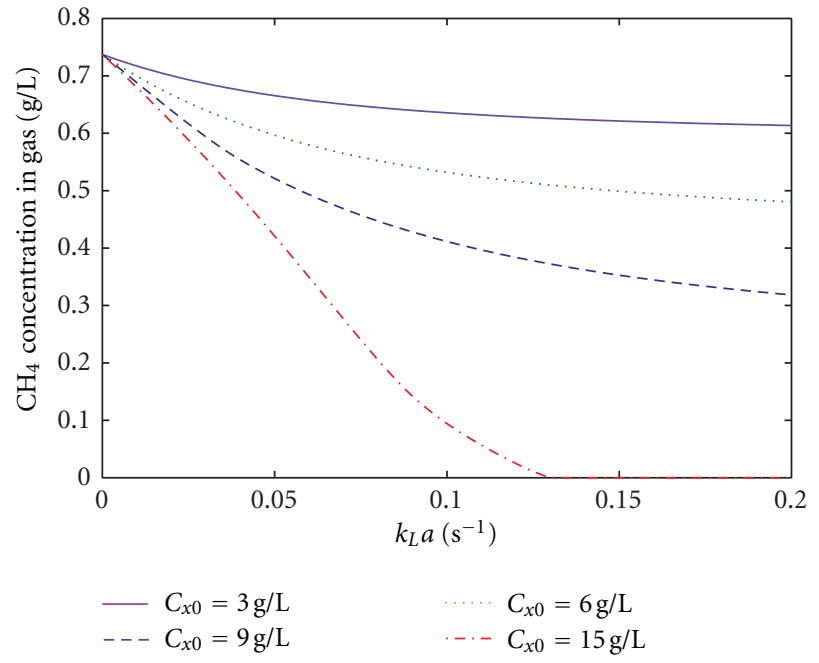

(b) Bubble methane concentration

FIGURE 6: Effect of the volumetric mass transfer coefficient on the concentration of oxygen and methane in the gas phase exiting the reactor ( $P_{T}=3 \mathrm{~atm}, G / L=0.20$, and $U_{L}=0.5 \mathrm{~m} / \mathrm{s}$ ).

concentration within the reactor to maintain a vigorous and healthy microorganism population.

The high-mass transfer coefficients needed to maintain a high level of reactor productivity cannot always be achieved, particularly in the case of shear-sensitive microorganisms. The use of high-operating pressures to promote mass transfer has been proposed as a mean for overcoming such difficulties. As can be seen from Figure 7, the production-rate per unit volume of the reactor was found to increase linearly with increasing operating pressure but tends to flatten off beyond a certain pressure the value of which depends on the cell loading. Operating the reactors at pressures higher than those optimal values is wasteful of energy, whereas the full productivity potential of the reactor will not be achieved by operating at pressures lower than the optimal. It is, however, important to remember that the volumetric flow rate of the gases flowing through the reactor decreases in proportion to the operating pressure, thereby making it more difficult to achieve and maintain elevated volumetric mass transfer coefficients at high pressures.

An extensive analysis of the results obtained revealed that productivity of the pipe-loop bioreactor is controlled mainly by the magnitude of the interphase mass transfer and the cell loading in the fermentation broth being introduced into the reactor. The combined effect of these two highly interactive parameters is given in Figure 8 which clearly illustrates the regions of mass transfer limitations, regions where the kinetics of microbial growth controls the overall performance, and the conditions where both of these parameters play an important role. 


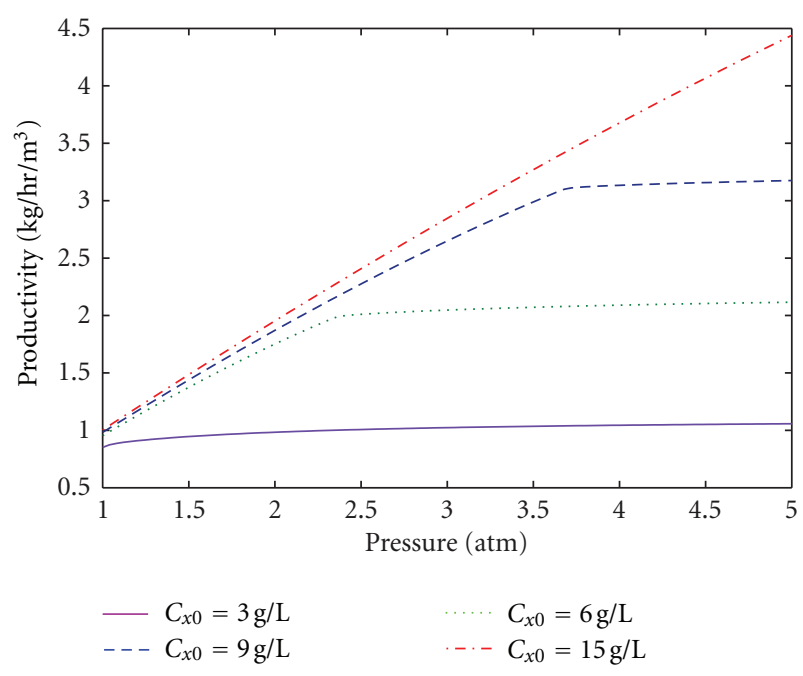

FIGURE 7: Effect of pressure on the reactor productivity for different cell loadings $\left(k_{L} a=0.025 \mathrm{~s}^{-1}, G / L=0.20\right.$, and $U_{L}=0.5 \mathrm{~m} / \mathrm{s}$ ).

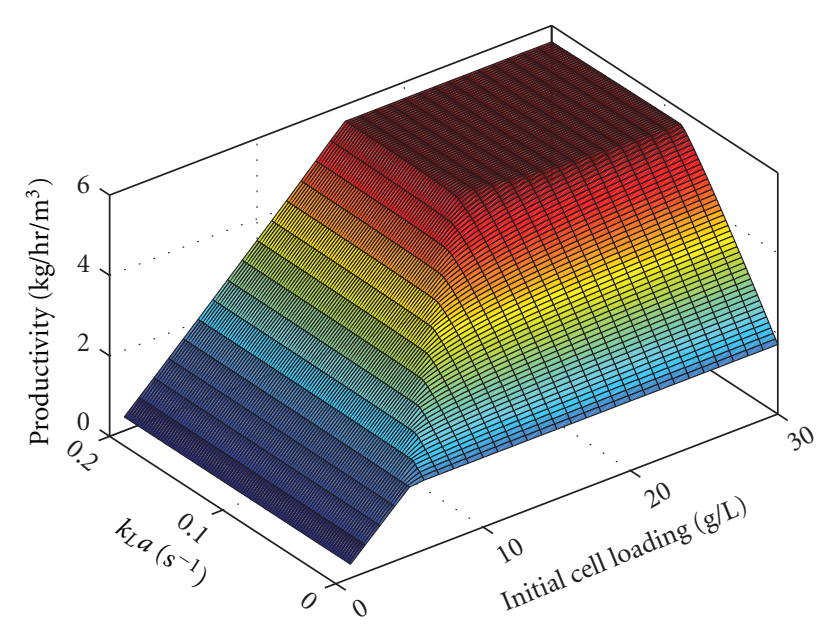

Figure 8: Effect of initial cell loading and volumetric mass transfer coefficient on the productivity of the bioreactor $\left(P_{T}=3 \mathrm{~atm}, G / L=\right.$ 0.20 , and $U_{L}=0.5 \mathrm{~m} / \mathrm{s}$ ).

A plateau in reactor productivity was observed to occur under conditions where both high biomass loadings, and elevated interphase mass transfer coefficients, can be achieved. In this region, an increase in the value of either parameter does not appear to enhance the productivity of the loopbioreactor mainly because the reactants are exhausted before reaching the end of the fixed length bioreactor $(15 \mathrm{~m})$. On the other hand, one can use shorter bioreactor length to match that where the bioactivity takes place, thereby reducing the capital cost of the bioreactor and increasing the productivity of the bioactive parts of the reactor.

Figure 8 clearly shows that bioreactor productivity as high as $4 \mathrm{~kg} / \mathrm{h} \mathrm{m}^{3}$ can be achieved using average mass transfer coefficients as low as $0.05 \mathrm{~s}^{-1}$, a feat that can be easily achieved using pipe-loop bioreactors that are equipped with appropriately designed static mixers. However, considering

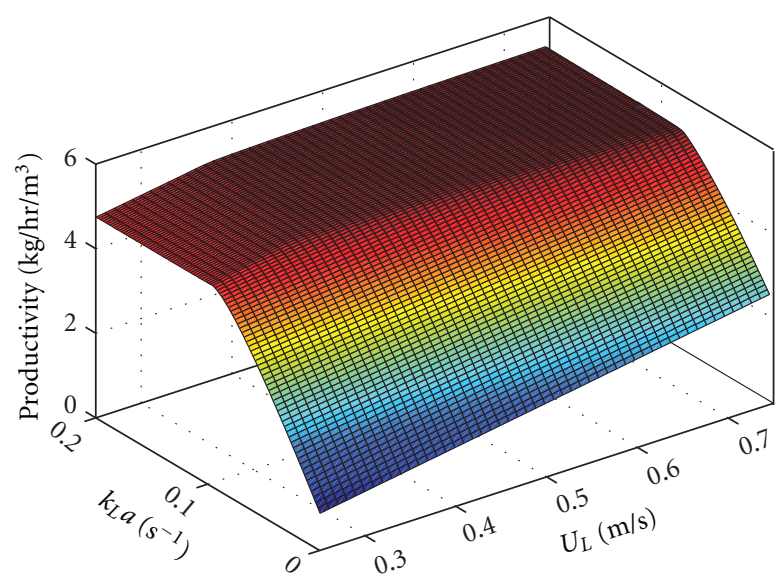

FIGURE 9: Effect of superficial liquid velocity and mass transfer coefficient on the productivity of the bioreactor $\left(P_{T}=3 \mathrm{~atm}, C_{x 0}=\right.$ $15 \mathrm{~g} / \mathrm{L}$, and $U_{G, 0}=0.043 \mathrm{~m} / \mathrm{s}$ ).

that there are in excess of 40 commercially available static mixers designs that can be used for that purpose, the detailed analysis/design of the gas liquid contact in such units is beyond the scope of the present investigation.

One of the most commonly used means for controlling the level of the interphase mass transfer coefficient in the case of gas/liquid dispersions flowing through static mixers is by increasing the superficial velocity of the liquid phase. The impact of such action on the productivity of the loop bioreactor is shown in Figure 9 for a fixed biomass loading of $15 \mathrm{~kg} / \mathrm{m}^{3}$ and a constant inlet superficial gas velocity of $U_{G}=$ $0.043 \mathrm{~m} / \mathrm{s}$.

Since we are dealing with a fixed length reactor, an increase in superficial gas velocity will lead to reducing the residence time in the bioreactor. It is therefore interesting to see that for $k_{L} a$ values $0.08 \mathrm{~s}^{-1}$, a plateau in the bioreactor productivity was observed to occur for superficial liquid velocities of $0.4 \mathrm{~m} / \mathrm{s}$ or higher. Under such conditions, all the reactants are converted within the specified reactor length and any changes in the residence time, $k_{L} a$, and $G / L$ ratio are not reflected in the productivity but in the length of the reactor needed to achieve conversion. The slight reduction in productivity observed at $U_{L}$ values lower than $0.4 \mathrm{~m} / \mathrm{s}$ is caused by the incomplete conversions of the reactants at the elevated $G / L$ ratios associated with the low liquid superficial velocities.

Under conditions where low $k_{L} a$ values are expected to prevail, it was found that the use of high liquid superficial velocities results in increasing the productivity of the reactor to some extent. This unexpected finding stems from the increased importance of the reactant feed rates associated with the elevated influx of presaturated liquid feed. This, in turn, resulted in the average concentration across the reactor length being higher the larger the liquid superficial velocity is, with the consequent increase in average bioreaction rate. It is, however, not desirable to operate the bioreactor outside of the plateau region because of the large reactant fraction that remains unutilized at the end of the reactor, and 
the consequent need to establish a costly reactant recovery system to maintain the sustainability of the operation.

\section{Conclusions and Recommendations}

The impact that mixing has on the productivity of growing microorganisms in loop bioreactors has been investigated using the bioconversion of natural gas into Single-Cell Protein as a case in point. A computer-aided design and simulation model capable of analyzing the factors affecting this process was developed which is capable of accounting for the impact that a wide range of operating and design conditions can have on the productivity of the tubular loopreactors used in industry.

The results obtained in this investigation suggest that it is possible to operate the process in a manner by which more than $99 \%$ of the reactants can be utilized in a oncethrough operation provided that proper biomass loadings and reactor lengths are used, and adequately high interphase mass transfer coefficients are achieved. Average bioreactor productivities in excess of $4 \mathrm{~kg} / \mathrm{h} \mathrm{m}^{3}$ are predicted to be achieved using average mass transfer coefficients as low as $0.05 \mathrm{~s}^{-1}$, a feat that can be easily achieved using pipe-loop bioreactors that are equipped with appropriately designed static mixers.

However, that model does not yet address the physical means by which the desired interphase mass transfer coefficients can be achieved, a deficiency that is presently being addressed.

\section{Nomenclature}

a: Interfacial area of contact $\left[\mathrm{m}^{2} / \mathrm{m}^{3}\right]$

$A_{c}$ : Cross-sectional area of the loop reactor pipe $\left[\mathrm{m}^{2}\right]$

C: Bulk concentration $[\mathrm{mol} / \mathrm{L}]$ and Constant in Van't Hoff equation $[\mathrm{L} \cdot \mathrm{atm} / \mathrm{mol}]$

$C^{*}$ : Equilibrium concentration at the interface [mol/L]

D: Pipe diameter $[\mathrm{m}]$

$E$ : $\quad$ Energy consumption rate $[\mathrm{kW}]$

$E_{m}$ : Energy consumed per unit mass of the liquid [kW/tonne]

$H$ : Henry's constant $[\mathrm{L} \cdot \mathrm{atm} / \mathrm{mol}]$

$k_{L}$ : Mass transfer coefficient in liquid phase $\left[\mathrm{m} \mathrm{s}^{-1}\right]$

$k_{L} a$ : Volumetric mass transfer coefficient $\left[\mathrm{s}^{-1}\right]$

$L: \quad$ Pipe length $[\mathrm{m}]$

$P$ : $\quad$ Pressure at any particular point along the reactor length [atm]

$Q: \quad$ Volumetric flow rate $\left[\mathrm{m}^{3} / \mathrm{s}\right]$

$R: \quad$ Universal gas constant $[\mathrm{L} \cdot \mathrm{atm} / \mathrm{K} \cdot \mathrm{mol}]$

Re: Pipe Reynolds number

$t$ : $\quad$ Residence time $[\mathrm{s}]$

T: $\quad$ Temperature $\left[{ }^{\circ} \mathrm{C}\right]$

$U: \quad$ Superficial velocity $[\mathrm{m} / \mathrm{s}]$

$V:$ Volume $\left[\mathrm{m}^{3}\right]$

$y$ : mole fraction in gas phase
$Y_{i j}$ : Stoichiometric yield coefficient of component $i$ relative to component $j$ (e.g., $\left.Y_{S X}, \operatorname{mol~CH} 4 / \mathrm{mol} \mathrm{Cells}\right)[\mathrm{mol} i / \mathrm{mol} j]$.

Greek Symbols

$\varepsilon$ : Local turbulent kinetic energy dissipation rate $[\mathrm{kW} /$ tonne]

$\varepsilon_{G}$ : Volumetric fraction of dispersed phase $[-]$

$\rho:$ Density $\left[\mathrm{kg} / \mathrm{m}^{3}\right]$

$\sigma$ : Surface tension $[\mathrm{N} / \mathrm{m}]$

$\tau$ : Total residence time in the reactor $[\mathrm{s}]$

$\mu$ : Viscosity $[\mathrm{cP}]$ and Specific growth rate of the microorganisms $\left[\mathrm{h}^{-1}\right]$

$\phi$ : Volumetric fraction of dispersed phase $[-]$.

Subscript

0: Initial conditions

$\mathrm{CH}_{4}$ : Methane

$\mathrm{CO}_{2}$ : Carbon dioxide

G: Gas

$\mathrm{H}_{2} \mathrm{O}$ : Water vapour

$i$ : $\quad$ Component $i$ in yield coefficient either produced or consumed (e.g., $S$ for substrate or $C$ for carbon dioxide)

Inert: Nonreactive gases

$j$ : $\quad$ Component $j$ in yield coefficient (e.g., $X$ )

L: $\quad$ Liquid

Max: Maximum

ref: Reference conditions

STP: Standard temperature and pressure $\left(25^{\circ} \mathrm{C}\right.$, $1 \mathrm{~atm})$

$T: \quad$ Total

$X: \quad$ Cell biomass.

\section{Acknowledgment}

The financial support of BGTT and NSERC is gratefully acknowledged.

\section{References}

[1] J. C. Merchuk and J. A. Asenjo, "The maned equation and mass transfer," Biotechnology and Bioengineering, vol. 45, no. 1, pp. 91-94, 1995.

[2] OECD, The Application of Biotechnology to Industrial Sustainability, OECD Publications, Paris, France, 2001.

[3] C. U. Ugwu, J. C. Ogbonna, and H. Tanaka, "Improvement of mass transfer characteristics and productivities of inclined tubular photobioreactors by installation of internal static mixers," Applied Microbiology and Biotechnology, vol. 58, no. 5, pp. 600-607, 2002.

[4] P. L. Rogers, Y. J. Jeon, and C. J. Svenson, "Application of biotechnology to industrial sustainability," Process Safety and Environmental Protection, vol. 83, no. 6B, pp. 499-503, 2005.

[5] J. Villadsen, "Innovative technology to meet the demands of the white biotechnology revolution of chemical production," 
Chemical Engineering Science, vol. 62, no. 24, pp. 6957-6968, 2007.

[6] M. Gavrilescu, R. V. Roman, and R. Z. Tudose, "Hydrodynamics in external-loop airlift bioreactors with static mixers," Bioprocess Engineering, vol. 16, no. 2, pp. 93-99, 1997.

[7] H. Eriksen, K. Strand, and L. Jorgenson, "Method of fermentation," GB Patent 0120025.2, Assigned to Statoil, Stavanger Norway, 2001.

[8] E. B. Larsen, "U-shaped and/or nozzle U-loop fermentor and method of carrying out a fermentation process," US Patent 6, 492, 135, 2002.

[9] A. M. Al Taweel, J. Yan, F. Azizi, D. Odedra, and H. G. Gomaa, "Using in-line static mixers to intensify gas-liquid mass transfer processes," Chemical Engineering Science, vol. 60, no. 22, pp. 6378-6390, 2005.

[10] F. Yazdian, S. A. Shojaosadati, M. Nosrati, M. R. Mehrnia, and E. Vasheghani-Farahani, "Study of geometry and operational conditions on mixing time, gas hold up, mass transfer, flow regime and biomass production from natural gas in a horizontal tubular loop bioreactor," Chemical Engineering Science, vol. 64, no. 3, pp. 540-547, 2009.

[11] D. F. Olsen, J. B. Jorgensen, J. Villadsen, and S. B. Jorgensen, "Optimal operating points for SCP production in the U-loop reactor," in Proceedings of the 9th International Symposium on Dynamics and Control of Process Systems (DYCOPS '10), M. Kothare, M. Tade, A. Vande Wouwer, and I. Smets, Eds., Leuven, Belgium, July 2010.

[12] A. Amanullah, B. C. Buckland, and A. W. Nienow, "Mixing in the fermentation and cell culture industries," in Handbook of Industrial Mixing Science and Practice, E. L. Paul, V. A. AtiemoObeng, and S. M. Kresta, Eds., John Wiley \& Sons, New York, NY, USA, 2004.

[13] M. Douaire, J. Morchain, and A. Liné, "Mini review: relationship between hydrodynamic conditions and substrate influx toward cells," in Proceedings of the 13th European Conference on Mixing, London, UK, April 2009.

[14] Y. K. Lee, "Microalgal mass culture systems and methods: their limitation and potential," Journal of Applied Phycology, vol. 13, no. 4, pp. 307-315, 2001.

[15] B. H. Um and Y. S. Kim, "Review: a chance for Korea to advance algal-biodiesel technology," Journal of Industrial and Engineering Chemistry, vol. 15, no. 1, pp. 1-7, 2009.

[16] C. Y. Chen, K. L. Yeh, R. Aisyah, D. J. Lee, and J. S. Chang, "Cultivation, photobioreactor design and harvesting of microalgae for biodiesel production: a critical review," Bioresource Technology, vol. 102, no. 1, pp. 71-81, 2011.

[17] A. Heyouni, M. Roustan, and Z. Do-Quang, "Hydrodynamics and mass transfer in gas-liquid flow through static mixers," Chemical Engineering Science, vol. 57, no. 16, pp. 3325-3333, 2002.

[18] I. Reynolds, "Laboratory protocol PI," in Proceedings of the 14th Process Intensification Network Meeting, BHR Group, Cranfield UK, November 2002.

[19] B. Weyand, M. Israelowitz, H. von Schroeder, and P. Vogt, "Fluid dynamics in bioreactor design: considerations for the theoretical and practical approach," in Bioreactor Systems for Tissue Engineering, C. Kasper, M. van Griensven, and R. Portner, Eds., pp. 251-268.

[20] R. Munter, "Comparison of mass transfer efficiency and energy consumption in static mixers," Ozone: Science \& Engineering, vol. 32, no. 6, pp. 399-407, 2010.

[21] A. Arwa, S. Baup, N. Gondrexon, J. P. Magnin, and J. Willison, "Enhancement of mass transfer characteristics and phenanthrene degradation in a two-phase partitioning bioreactor equipped with internal static mixers," Biotechnology and Bioprocess Engineering, vol. 16, no. 2, pp. 413-418, 2011.

[22] C. Zhong and Y. J. Yuan, "Responses of Taxus cuspidata to hydrodynamics in bubble column bioreactors with different sparging nozzle sizes," Biochemical Engineering Journal, vol. 45, no. 2, pp. 100-106, 2009.

[23] S. Schmalzriedt, M. Jenne, K. Mauch, and M. Reuss, "Integration of physiology and fluid dynamics," Advances in Biochemical Engineering/Biotechnology, vol. 80, pp. 19-68, 2003.

[24] F. Garcia-Ochoa and E. Gomez, "Bioreactor scale-up and oxygen transfer rate in microbial processes: an overview," Biotechnology Advances, vol. 27, no. 2, pp. 153-176, 2009.

[25] C. Lu, F. G. Acién Fernández, E. Cañizares Guerrero, D. O. Hall, and E. Molina Grima, "Overall assessment of Monodus subterraneus cultivation and EPA production in outdoor helical and bubble column reactors," Journal of Applied Phycology, vol. 14, no. 5, pp. 331-342, 2002.

[26] A. H. Scragg, A. M. Illman, A. Carden, and S. W. Shales, "Growth of microalgae with increased calorific values in a tubular bioreactor," Biomass and Bioenergy, vol. 23, no. 1, pp. 67-73, 2002.

[27] F. Yazdian, M. P. Hajiabbas, S. A. Shojaosadati, M. Nosrati, E. Vasheghani-Farahani, and M. R. Mehrnia, "Study of hydrodynamics, mass transfer, energy consumption, and biomass production from natural gas in a forced-liquid vertical tubular loop bioreactor," Biochemical Engineering Journal, vol. 49, no. 2, pp. 192-200, 2010.

[28] R. K. Thakur, C. Vial, K. D. P. Nigam, E. B. Nauman, and G. Djelveh, "Static mixers in the process industries-a review," Chemical Engineering Research and Design, vol. 81, no. 7, pp. 787-826, 2003.

[29] L. Oshinowo and D. C. S. Kuhn, "Turbulence decay behind expanded metal screens," Canadian Journal of Chemical Engineering, vol. 78, no. 6, pp. 1032-1039, 2000.

[30] F. Azizi and A. M. Al Taweel, "Population balance simulation of gas-liquid contacting," Chemical Engineering Science, vol. 62, no. 24, pp. 7436-7445, 2007.

[31] A. W. M. Roes, A. J. Zeeman, and F. H. J. Bukkems, "High intensity gas/liquid mass transfer in the bubbly flow region during co-current upflow through static mixers," vol. 87 of Institution of Chemical Engineers Symposium Series, pp. 231238, 1984.

[32] I. Turunen and H. Haario, "Mass transfer in tubular reactors equipped with static mixers," Chemical Engineering Science, vol. 49, no. 24, pp. 5257-5269, 1994.

[33] A. R. Toader, P. Hamersma, and R. F. Mudde, "Mass transfer in static mixers," in Proceedings of the 10th International Gas Liquid Solid Reactor Engineering Conference, Praga, Portugal, June 2011.

[34] F. Azizi and A. M. Al Taweel, "Intensifying gas-liquid mass transfer operations," in Proceedings of the 8th European Congress of Chemical Engineering, Berlin, Germany, September 2011.

[35] G. Hebrard, J. Zeng, and K. Loubiere, "Effect of surfactants on liquid side mass transfer coefficients: a new insight," Chemical Engineering Journal, vol. 148, no. 1, pp. 132-138, 2009.

[36] T. Lemenand, P. Dupont, D. Della Valle, and H. Peerhossaini, "Turbulent mixing of two immiscible fluids," Journal of Fluids Engineering, Transactions of the ASME, vol. 127, no. 6, pp. 1132-1139, 2005.

[37] C. Israelidis, "Nutrition-Single Cell Protein, Twenty Years Later,” 2006, http://www.biopolitics.gr/BIOPOLITICS/ HTML/PUBS/VOL1/isreali.htm. 
[38] K. Rostami, M. T. Moazed, D. Zareh, and A. Kheirolomoom, "Single cell protein production using airlift reactor containing static mixer," in Journal of Bioscience and Bioengineering, vol. 108, pp. 1389-1723, 2009.

[39] J. Nielsen, J. Villadsen, and G. Liden, Bioreaction Engineering Principles, Kluwer Academic/Plenum Publishers, 2003.

[40] L. Joergensen and H. Degn, "Growth rate and methane affinity of a turbidostatic and oxystatic continuous culture of Methylococcus capsulatus (Bath)," Biotechnology Letters, vol. 9, no. 1, pp. 71-76, 1987.

[41] K. S. Jun and S. C. Jain, "Oxygen transfer in bubbly turbulent shear flow," Journal of Hydraulic Engineering, vol. 119, no. 1, pp. 21-36, 1993.

[42] K. Podila, A. M. Al Taweel, M. Koksal, A. Troshko, and Y. P. Gupta, "CFD simulation of gas-liquid contacting in tubular reactors," Chemical Engineering Science, vol. 62, no. 24, pp. 7151-7162, 2007.

[43] J. Klein, J. Maia, A. A. Vicente, L. Domingues, J. A. Teixeira, and M. Jurašč́k, "Relationships between hydrodynamics and rheology of flocculating yeast suspensions in a high-celldensity airlift bioreactor," Biotechnology and Bioengineering, vol. 89, no. 4, pp. 393-399, 2005. 

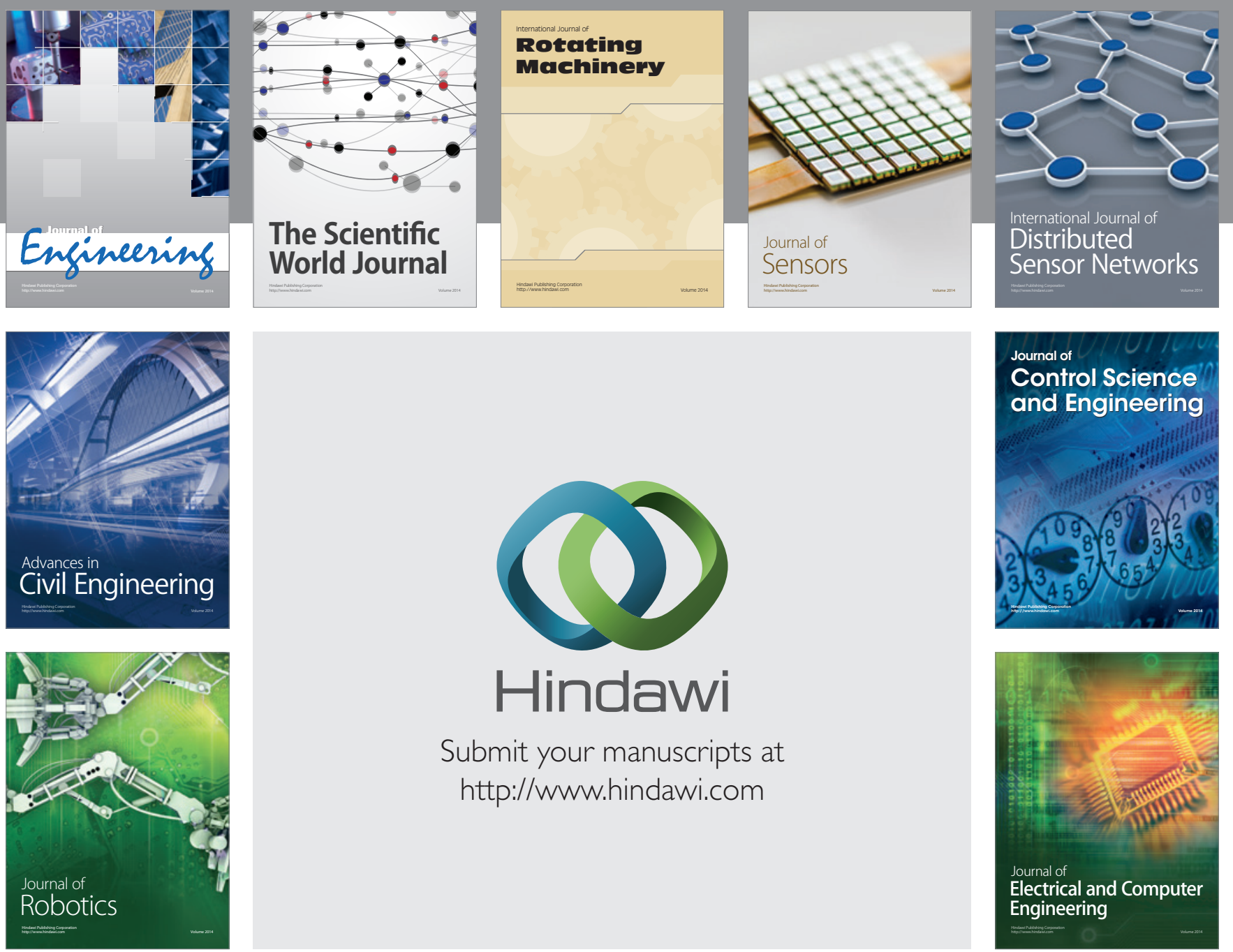

Submit your manuscripts at

http://www.hindawi.com
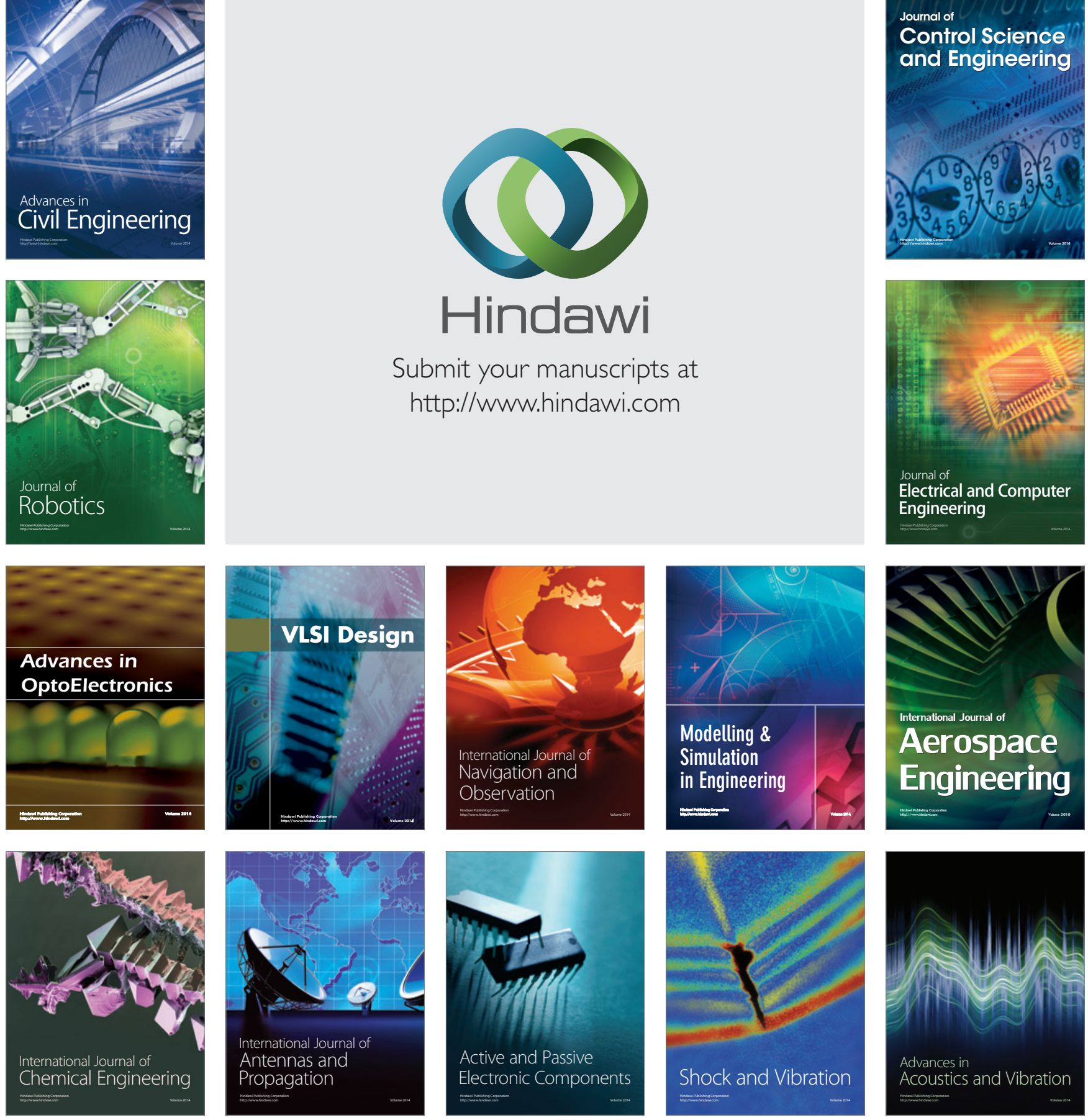